\title{
Excellent emergency medicine educators adapt teaching methods to learner experience level and patient acuity
}

\author{
Kristi H. Grall1, Ilene B. Harris², Deborah Simpson'3, Mark Gelula², Jaime Butler", \\ Edward P. Callahan 5 \\ ${ }^{1}$ Department of Emergency Medicine, University of Arizona, USA \\ ${ }^{2}$ Department of Medical Education, University of Illinois at Chicago, USA \\ ${ }^{3}$ Academic Administration, Aurora Health Care-Milwaukee, USA \\ ${ }^{4}$ Department of Emergency Medicine, Providence Alaska Medical Center/University of Washington-Anchorage, USA \\ ${ }^{5}$ Department of Emergency Medicine, Medical College of Wisconsin, USA
}

Correspondence: Kristi J.H. Grall, University of Arizona Medical Center at South Campus, HK Abrams Annex, Department of Emergency Medicine Tucson, Arizona, 85713, USA. Email: khgrall@aemrc.arizona.edu

Accepted: May 04, 2013

\begin{abstract}
Objectives: This study investigates whether instructional methods used by excellent emergency medicine residency teachers change with changing conditions of learner level of training, patient acuity and department census.

Methods: Four excellent, purposively selected, emergency medicine teachers consented to participate in this nonparticipant observational study. Teachers were observed for 32 hours in the emergency department, using a structured observation form focused on: teaching methods used, context learner level of training, emergency department patient census and patients' illness severity. Data was analyzed qualitatively using constant comparative analysis.

Results: Fifteen (15) categories of teaching methods were observed. The 4 most frequently observed methods were: Questioning (used in $47 \%$ of teaching encounters), Advice Giving (33\%), Limited Teaching Points (31\%) and Patient Updates (22\%). Patient Updates were more often used with
\end{abstract}

senior residents. Multiple methods were used in most encounters. Teaching methods did not vary significantly with increased emergency department volume, but faculty and residents relied more heavily on a single method of teaching per encounter as patient acuity increased to Triage levels One and Two.

Conclusions: Excellent emergency medicine teachers teaching methods were classified into 15 categories. They typically rely heavily on four methods, adapting to resident training level and patient illness severity, rather than patient volume. The observed teaching methods provide teachers who have high clinical productivity expectations and/or demanding emergency care settings with an enriched repertoire of teaching strategies.

Keywords: Graduate medical education, clinical teaching, emergency medicine

\section{Introduction}

Excellent clinical teaching requires time. ${ }^{1,2}$ However, surveys of emergency medicine (EM) faculty demonstrate that they have difficulty finding time to teach, a phenomenon perceived to be associated with increased demands for clinical productivity, ${ }^{3}$ when emergency departments (ED) across the country are faced with overcrowding due to ever increasing patient volumes. ${ }^{4}$ There are few empirical studies of the effects of overcrowding on ED teaching and learning.
Some authors have hypothesized a negative relationship. ${ }^{3,5}$ Other authors describe strategies for teaching at the bedside in the ED environment. ${ }^{6}$ Recent surveys demonstrate little to no effect of crowding on quality of teaching. ${ }^{7,8}$ Nevertheless, many EM attending physicians still believe that the attention and time used to care for patients in a crowded ED diminishes the time available for teaching. ${ }^{3}$ To date, scholars who study ED teaching have used survey and 
interview methods, but not observation. To address the literature gap for observation-based studies of teaching residents in high volume, rapid flow, urgent settings like the ED, we selected four excellent EM teachers, based on peer teachers' and residents' assessments, and observed their teaching to address the question: do instructional methods used by excellent emergency medicine (EM) residency teachers change with changing conditions of learner level of training, patient acuity and department census?

\section{Methods}

A primarily qualitative, non-participant observational study was conducted from April to June 2006 at the Medical College of Wisconsin (MCW)/ Froedtert Hospital Emergency Department in Milwaukee, Wisconsin. This study was reviewed by institutional review boards (IRBs) at both the Medical College of Wisconsin where the research was performed and the University of Illinois - Chicago where the research was used as part of a graduate thesis, and was granted "exempt" status by both. The three-year Emergency Medicine residency training program accepts nine residents per year and is located at a Level 1 trauma center. The ED is staffed by two attending EM physicians, three resident physicians, and a medical student, so the distribution of residents on service during all observations was constant. Each attending, on average, supervises two learners (two residents or one resident and one student) on any given shift. All patients are interviewed, examined and cared for by residents and staffed with attendings. These attendings have ultimate responsibility for the patients' care, and are also responsible for maintaining ED patient flow.

A purposive sampling procedure was used to select four full-time EM faculty members for participation, in order to achieve thematic saturation. EM faculty members were asked via an e-mailed survey to identify the three best teachers in their department. Simultaneously, residents' evaluations of ED teachers were reviewed and yielded six faculty with the highest mean ratings for excellence in teaching, consistently over the prior three years. Comparing the two data sets, four ED teachers were identified and consented to participate in this study.

The initial framework for observation, using a structured observation form, was derived from the teaching methods described by Bandiera and colleagues, based on their interview study, ${ }^{3,10}$ augmented with selected teaching methods identified for ambulatory teaching, based on Heidenreich and colleagues' literature review study, with plans to add categories based on pilot testing the form and observation of the ED teachers. ${ }^{9}$ Prior to data collection, the structured observation form was piloted in the ED by two authors, with inter-observer discussion and comparisons (KG/DS). Two observers (KG/JB) were then trained to record the four exemplary teachers' behaviors on the structured observation form. Training was conducted in two education sessions held prior to data collection, including both review of a coding manual developed from the pilot study and practice observations with comparisons, until observers reached $90 \%$ agreement in their coding.

During the data collection, each teacher was observed in their teaching role for 8 non-consecutive hours, for a total of 32 hours of observations. Each observation period began with an adaption period, during which the observer recorded no notes, but observed the teachers in their roles, in order to get the instructors used to having someone observing them and have them act more naturally in the environment. Observers were required to take a scheduled 10minute break after two hours of continuous observation to reduce fatigue. Observations were recorded in three-minute time intervals, with recording conducted in real time, including: coding for previously described teaching methods; contextual descriptions; and coding for demographic/ED environment variables including - resident's level of training (PGY1-PGY3), the number of occupied ED beds (proxy for ED crowding), and if the teaching concerned patient care the patient's triage code (proxy for patient complexity and illness severity). See Table 1 for Coding Categories and Demographics collected. Each teaching method was coded only once per teaching encounter (defined as an encounter between resident and faculty which involved teaching), but multiple methods could be coded during the same teaching encounter.

Table 1. Coding categories and demographic data

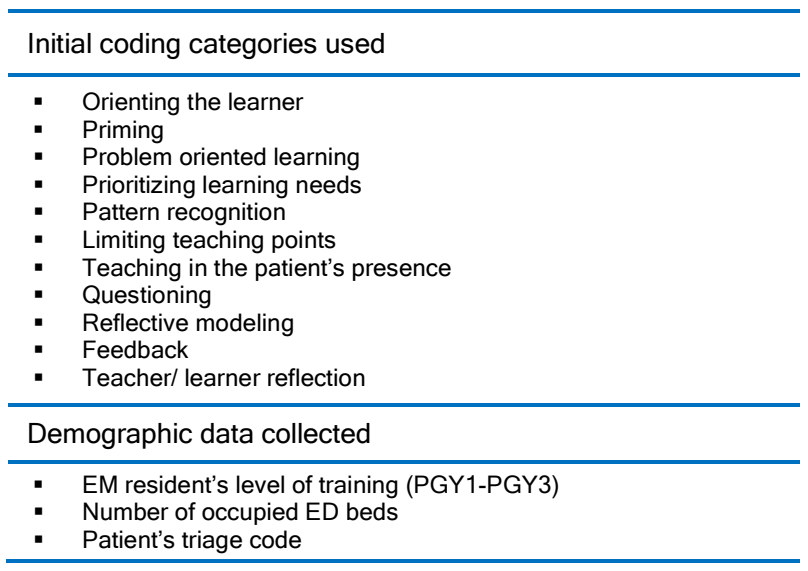

Data from the observations included category check-offs as well as field notes. The data was analyzed using constant comparative analysis, which is associated with grounded theory methods. ${ }^{11}$ Line-by-line analysis of the field notes was done by two of the authors, and subsequent themes identified were then organized into categories that were labeled with codes. If the observation fit in one of the preexisting categories, it was coded as such. If an observation did not fit into a pre-existing category, and was consistent with the definition of a behavior observed in a teaching encounter that was deliberately used with intention to educate a resident, a new theme/category was created and added to the set of categories. The categories/themes were 
revisited repeatedly, until no further themes were identified, indicating that saturation had been reached.

Using constant comparative analysis ${ }^{11}$ we were able to identify relationships between the specific teaching methods used and other variables potentially affecting teaching and learning, including: learner level of training, emergency department crowding status, and patient illness severity. The associations and trends that were identified in the data were compared with all instances of these associations, for consistency of analysis. Behaviors were then organized by their relationship to extant literature, i.e., already described as clinical teaching behaviors in the ambulatory and/or emergency medicine settings, or "other", if not previously found in the literature.

\section{Results}

One hundred sixty-two (162) faculty/resident teaching encounters, defined as an encounter between resident and faculty which involved teaching, were observed during the 32 hours of observation. Twenty-nine (29) of these encounters involved first year residents (PGY-1), 57 encounters involved second year residents (PGY-2), and 81 encounters involved third year residents (PGY-3). As some encounters involved more than one resident at a time, the sum of residents exceeds the number of observations. Ninety-six (59\%) encounters were recorded when the ED was considered full capacity or $>20$ beds occupied, while 66 (41\%) encounters were observed when the ED had less than or equal to 20 beds occupied. From the observed teaching encounters, 14 categories of teaching methods were identified; eight (8) were methods previously described in the literature and six (6) were methods that have not been previously described in the literature on clinical teaching methods. The teaching methods, their frequency of use and a brief description are presented in Table 2, organized by whether they were previously identified in the literature or identified as "other" methods. Four teaching methods were both the most frequently used by individual participants and collectively across participants: Questioning (47\% of total encounters), Advice Giving (33\%), Limited Teaching Points (31\%), and Patient Updates (22\%). The most commonly used method, Questioning, was used with residents at all three levels of training (PGY-1, PGY-2, PGY-3), across patient severity levels (triage code levels 2-4), and ED volume (e.g., moderate volume with $<20$ beds occupied to full capacity with $>20$ beds occupied).

In general, teaching time with PGY-3 residents (final year) was briefer and more task-oriented, but the most commonly used teaching methods were still used, in an adapted form. Less time consuming teaching methods (e.g., Affirmatives, Information Sharing, and Patient Updates) were used primarily with third year residents. Other methods, such as Teaching in the Patient's Presence, were not used with PGY3s. Increased ED volume did not correlate with teaching methods used, although there was a trend for the participating teachers to use less time consuming, and potentially more efficient, methods (e.g., Advice Giving, Patient Updates) with increased crowding. This trend was not as strong as was the trend for expert teachers to alter their teaching methods selected for resident level of training. However, there was no change in overall frequency of use for the four most commonly used teaching methods (i.e., Questioning, Advice Giving, Limited Teaching Points, Patient Updates) relative to ED volume.

In our observations, teachers typically relied more heavily on one method per teaching encounter with more severely ill patients (i.e., Triage Levels One to Two). Limited Teaching Points was used more frequently with sicker patients, and Patient Updates appeared to be used more frequently with Triage Levels Three to Five patients. Table 3 presents the percent of use of the four most frequently used teaching methods in relation to these variables.

\section{Discussion}

Few studies have focused on effective ED teaching, with no observation-based studies published to date. Bandiera and colleagues identified 12 effective ED teaching strategies, based on structured interviews with Canadian award winning EM faculty selected by their department chair. ${ }^{3}$ More generally, efficient and effective teaching practices have been described in the ambulatory care education literature. An exhaustive review article classified teaching methods viewed as efficient and effective in ambulatory care into 11 distinct methods, but the observation- based studies included in this review did not occur in the ED environment. Expert ED teachers relied heavily on four teaching methods under most conditions: Questioning, Advice Giving, Limited Teaching Points, and Patient Updates. There were minor variations for learner level of training and patient illness severity, but not ED volume, consistent with recent literature, which asserts that "skilled instructors" continued to teach well, "regardless of how busy they were".

Questioning, the most frequently used teaching method, was identified by Heidenreich ${ }^{9}$ and Ramani ${ }^{12}$ to be efficient and effective, and was often observed as a means to "identify the learners' needs." ${ }^{\prime 3}$ However, this is the first time that questioning has been explicitly observed as a commonly used teaching method in the ED environment. The question focus varied from narrow questions, yielding specific information for further scrutiny or questions assessing residents' knowledge base ${ }^{13}$ (e.g., "It's been there how long? Where?" and "What else do you worry about with...?"), to broad questions, used as a trigger to stimulate critical thinking, discussion, resident problem solving skills and patient management guidance (e.g., "What else should we do for him?"). Further research in the ED environment, focused on use of specific question types, should be conducted to determine the frequency and purpose of different questions in the ED. 


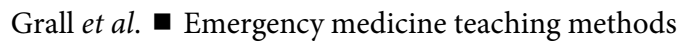

Table 2. Teaching methods, definitions and frequency of use in high volume, high flow urgent patient setting

\begin{tabular}{|c|c|c|c|}
\hline Method & Definition & Examples & $\begin{array}{l}\text { Teaching method } \\
\text { applied } \\
\mathrm{n}(\%)\end{array}$ \\
\hline \multicolumn{4}{|c|}{ Methods previously reported in literature } \\
\hline Questioning & $\begin{array}{l}\text { - } \quad \text { Challenges resident using questions. } \\
\text { - Assesses resident's knowledge } \\
\text { using questions. }\end{array}$ & $\begin{array}{l}\text { - "It's been there how long? Where?" } \\
\text { - "Do you need any interventions on her now?" } \\
\text { - "What are you going to do with this information?" }\end{array}$ & $76(47)$ \\
\hline Limited teaching points & $\begin{array}{l}\text { - Focuses teaching on 1-2 key } \\
\text { concepts. } \\
\text { - } \\
\text { Oonger discussion than Problem Learning and less related to } \\
\text { specific problem of current patient. }\end{array}$ & $\begin{array}{l}\text { - Discussion limited to local anesthetics and their } \\
\text { property of duration of action. } \\
\text { - } \quad \text { Discusses sedation of patients with resident. }\end{array}$ & $50(31)$ \\
\hline $\begin{array}{l}\text { Teaching in the } \\
\text { patient's presence }\end{array}$ & $\begin{array}{l}\text { - Teaches in the presence of patients. } \\
\text { Bedside teaching. }\end{array}$ & $\begin{array}{l}\text { - Simultaneous physical examination with PGY-2. } \\
\text { - Correction of resident's ultrasound technique at } \\
\text { bedside. }\end{array}$ & $18(11)$ \\
\hline $\begin{array}{l}\text { Problem oriented } \\
\text { learning }\end{array}$ & $\begin{array}{l}\text { - Encourages learning from specific } \\
\text { patient problems or management is- } \\
\text { sues. } \\
\text { - Seeks out teachable moments and } \\
\text { deliberately selects teaching cases } \\
\text { to make important teaching points. }\end{array}$ & $\begin{array}{l}\text { - } \quad \text { Calculation of dosing for PCA pump. } \\
\text { - RN shows critical lab values to resident and } \\
\text { faculty. Resident discusses with attending how } \\
\text { he is going to manage this new problem. }\end{array}$ & $17(11)$ \\
\hline Reflective modeling & $\begin{array}{l}\text { - Uses reflection on own practice to } \\
\text { teach. Teaches from own experienc- } \\
\text { es. } \\
\text { - Explains own thought processes. }\end{array}$ & $\begin{array}{l}\text { - Thinks aloud through patient presentation and } \\
\text { differential diagnosis alternatives, while resident } \\
\text { listens. } \\
\text { "I took care of a patient a year ago like this." } \\
\text { "..ok, per our last discussion, this is likely vi- } \\
\text { ral...his vital signs are stable... he's young and } \\
\text { healthy... probably not pneumonia... so he can be } \\
\text { discharged." }\end{array}$ & $16(10)$ \\
\hline Pattern recognition & $\begin{array}{l}\text { - } \quad \text { Requests chief complaint and } \\
\text { presumptive diagnosis before hear- } \\
\text { ing entire case. } \\
\text { - } \quad \text { Asks for differential diagnosis. }\end{array}$ & $\begin{array}{l}\text { - "What's your differential?" } \\
\text { - Changes scenario from initial patient encounter, } \\
\text { then asks, "What now?" }\end{array}$ & $14(9)$ \\
\hline Priming & $\begin{array}{l}\text { - Orients and focuses residents just } \\
\text { prior to seeing the patient. }\end{array}$ & $\begin{array}{l}\text { - Gives patient history from previously obtained } \\
\text { information from primary physician phone call. } \\
\text { - Waiting for trauma patient to arrive, asks resident, } \\
\text { "What are you going to do when he gets here?" }\end{array}$ & $14(9)$ \\
\hline Feedback & $\begin{array}{l}\text { - } \quad \text { Specifies, "This is feedback..." } \\
\text { - } \quad \text { Describes specific behaviors that } \\
\text { need improvement }\end{array}$ & $\begin{array}{l}\text { - "You need to prioritize better.... you need to look } \\
\text { - "Ya the chart early on and get things started." } \\
\text { patients moving." } \\
\text { - "This patient should be on your, 'what do I need to } \\
\text { admit them?' list, sooner rather than later." }\end{array}$ & $9(6)$ \\
\hline
\end{tabular}

New - previously unreported - methods

\begin{tabular}{|c|c|c|c|}
\hline Advice giving & $\begin{array}{l}\text { - Gives resident advice on various } \\
\text { aspects of patient care. }\end{array}$ & $\begin{array}{l}\text { - Tells resident, "Do this ...I would talk to them } \\
\text { about..." } \\
\text { Tells resident to use marcaine for laceration } \\
\text { repair as it lasts longer than lidocaine. } \\
\text { "In this case I would give him oxycodone, be- } \\
\text { cause the patient was abandoned by his primary } \\
\text { doctor." }\end{array}$ & $54(33)$ \\
\hline Patient updates & $\begin{array}{l}\text { Resident gives update of patient } \\
\text { information, in quick encounters, re- } \\
\text { garding previously staffed patients } \\
\text { and attending provides reassurance } \\
\text { re: management. }\end{array}$ & $\begin{array}{l}\text { Running the board: Includes each patient, and } \\
\text { their current work up status. } \\
\text { - Reviews care thus far. }\end{array}$ & $36(22)$ \\
\hline Affirmatives & $\begin{array}{l}\text { Provides short affirmative answers } \\
\text { (yes, ok) and/or nods as resident re- } \\
\text { lates patient history/physical exam } \\
\text { data. }\end{array}$ & $\begin{array}{l}\text { - Regarding X-ray findings. "Yes, I agree with you." } \\
\text { "Your history is good. I got the same history." }\end{array}$ & $24(15)$ \\
\hline Information sharing & $\begin{array}{l}\text { - Attending shares further patient- } \\
\text { related information that he has dis- } \\
\text { covered independently. (Attending } \\
\text { initiated) }\end{array}$ & $\begin{array}{l}\text { - Gives resident patient's lab and old chart history. } \\
\text { "Remember our patient with Crohn's disease..." }\end{array}$ & $18(11)$ \\
\hline $\begin{array}{l}\text { Demonstration / role } \\
\text { modeling }\end{array}$ & $\begin{array}{l}\text { - Demonstrates or models the role of } \\
\text { emergency medicine physician with } \\
\text { resident directly observing. }\end{array}$ & $\begin{array}{l}\text { - Completes physical exam while asking patient } \\
\text { historical questions as resident observes. } \\
\text { Demonstrates further physical exam while } \\
\text { resident observes. } \\
\text { Demonstrates hare splint removal. Assists with } \\
\text { log roll. }\end{array}$ & $15(9)$ \\
\hline Mini-lecture & $\begin{array}{l}\text { - Provides short (1-2 minute) "lec- } \\
\text { tures" or discussions focusing on } \\
\text { one topic. }\end{array}$ & $\begin{array}{l}\text { - } \quad \text { Carbon Monoxide effects, levels, management. } \\
\text { abdominal pain. }\end{array}$ & $7(4)$ \\
\hline
\end{tabular}

${ }^{*}$ Does not equal $100 \%$, as most teaching encounters involved more than one teaching method and were coded as such. 
Advice Giving was sometimes solicited by the residents (e.g., "What do you want me to do for this patient?") to inform the resident's patient care management. Other times, the teacher provided unsolicited advice for corrective purposes (e.g., Teacher tells the resident to" use marcaine for (a) laceration repair as it lasts longer"). Advice Giving may be an efficient method because it does not add additional steps to patient care and is consistent with principles of learning (i.e., immediately applicable, built on prior knowledge). ${ }^{14}$ Advice Giving can also be used for corrective purposes as a form of feedback. ${ }^{15}$ However, the degree to which study participants intended Advice Giving as corrective feedback was not elicited in our study. Further research is needed to explore Advice Giving as a distinct teaching method, versus a mechanism for providing corrective feedback, given its unique identification in this observationbased study and its omission in prior studies due to their reliance on self-reported teaching methods.

Table 3. Four most common used teaching methods by resident level, ED volume (beds occupied) and patient triage severity

\begin{tabular}{|c|c|c|c|c|}
\hline \multirow{2}{*}{$\begin{array}{l}\text { Variable } \\
\text { Resident training level }^{\dagger}\end{array}$} & \multicolumn{4}{|c|}{ Most common methods } \\
\hline & $\begin{array}{l}\text { Ques } \\
\text { tion- } \\
\text { ing }\end{array}$ & $\begin{array}{l}\text { Advice } \\
\text { giving }\end{array}$ & $\begin{array}{l}\text { Limited } \\
\text { teach- } \\
\text { ing } \\
\text { points }\end{array}$ & $\begin{array}{l}\text { Patient } \\
\text { up- } \\
\text { dates }\end{array}$ \\
\hline PGY-1 & $41 \%$ & $32 \%$ & $32 \%$ & $18 \%$ \\
\hline PGY-2 & $47 \%$ & $42 \%$ & $45 \%$ & $11 \%$ \\
\hline PGY-3 & $51 \%$ & $32 \%$ & $24 \%$ & $28 \%$ \\
\hline Multiple learners & $80 \%$ & $20 \%$ & $20 \%$ & $60 \%$ \\
\hline \multicolumn{5}{|l|}{ Number of beds occupied } \\
\hline$>20$ & $46 \%$ & $39 \%$ & $30 \%$ & $24 \%$ \\
\hline$<20$ & $54 \%$ & $31 \%$ & $37 \%$ & $20 \%$ \\
\hline \multicolumn{5}{|c|}{ Patient triage severity level ${ }^{\ddagger}$} \\
\hline Level 1-2 & $54 \%$ & $43 \%$ & $46 \%$ & $16 \%$ \\
\hline Level 3-5 & $48 \%$ & $32 \%$ & $28 \%$ & $24 \%$ \\
\hline \multicolumn{5}{|c|}{ 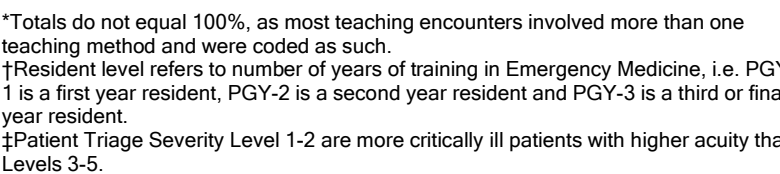 } \\
\hline
\end{tabular}

Limited Teaching Points, typically related to a specific aspect of a patient's care (e.g., "discusses patient discharge plans with resident.") in very condensed, problem focused, teaching interactions, was previously described by Heidenreich and Bandiera. ${ }^{3,9}$ Limited Teaching Points can be selected by targeting teaching to specific needs of learners, through the use of teaching scripts, which are defined sets of pedagogical knowledge that relate to a patient's specific illness. ${ }^{16}$ Further research should be done to determine how excellent emergency medicine teachers select these teaching points.

Patient Updates are easier to use with less complicated patients, perhaps explaining their preferred use with less severely ill patients; and their brevity makes them attractive for promoting efficiency, yet they have not been previously identified as a teaching method. In a Patient Update, a resident quickly provides information regarding previously staffed patients, which becomes a basis for teachers to reinforce (or amend) the resident's patient care plan, allowing the resident to critically reflect on the appropriateness of their management. Though resident initiated, these update focused teaching encounters kept teaching faculty abreast of the current status of all the patients in the department simultaneously, while allowing the resident to develop the ability to multi-task. Teaching and learning goals are context dependent. ${ }^{17}$ The ED differs from the ambulatory setting in that presentations "by nature must be more concise and to the point without sacrificing essential information." 18 Further research should be targeted at determining how ED residents develop multi-tasking skills leading to ED situational awareness through Patient Updates. In addition to the 4 most frequently used teaching methods described above, these teachers used 10 other teaching methods. Many of these methods, as well as those previously discussed, are components of several clinical teaching models (One Minute Preceptor, SNAPPS, AuntMinnie) that have been demonstrated to achieve greater learning in minimal time. ${ }^{13,18-23}$ Due to the infrequent use of these teaching methods in this study, further research specific to their usefulness in the ED is needed.

While this study was conducted seven years ago, the perceptions of ED crowding and limited time for teaching remain, while the demands on EM physicians seem to be at an all-time high. Thus, exploring whether instructional methods used by excellent emergency medicine (EM) residency teachers change with changing conditions of learner level of training, patient acuity and department census remains an important and timely educational question. We opted to observe four excellent EM teachers; a control group of not so excellent EM faculty may have provided additional information and further generalizability, and such action research is a planned future project to explore this possibility. Additionally we must consider the possibility that teaching methods used by "excellent" teachers may not lead to the best educational outcomes; however, we make this assumption based on emerging evidence that physicians' clinical teaching quality has an impact on learners' performance. ${ }^{24}$ Further studies should address if there is an association between these teaching methods and improved learning outcomes.

In general, participant reactivity, or participants changing their behavior in response to being observed, ${ }^{25-27}$ can be a limitation of any observation study. This impact was reduced by the adaptation period included in the study design. In addition, an observer training session held prior to the start of data collection, standardized data collection procedures, and a Coding Manual to define the observer role addressed many of the potential observer biases. Observation schedules were used, with scheduled break periods, to reduce observer fatigue. ${ }^{25}$ 
In addition, as is typical of exploratory, observational studies, designed to provide descriptive information in order to generate new hypotheses and inform subsequent studies, sampling is an issue. Although a purposive sampling procedure was used, the sampling is a limitation, given the single study site, the number of expert teachers observed and the number of observations. Using a prespecified list for observations (as is listed in Figure 1) may have led observers to use these categories rather than to think more openly and potentially create make comments suggesting other categories, despite Observer Training that occurred prior to any recordings.

To avoid over-representation of some methods such as Questioning and to avoid rating errors (e.g., having to determine when one instance of a method ended and another instance began), each method was coded once per teaching encounter. As a result, there may be sampling errors. In addition, since the majority of observations (59\%) occurred when the ED was "at high capacity", inferences made about teaching when the ED was not "crowded" may need further study.

\section{Conclusions}

This observational study of excellent emergency medicine teachers was conducted to determine whether instructional methods used by excellent emergency medicine (EM) residency teachers change with changing conditions of learner level of training, patient acuity and department census. We found that excellent ED teachers relied heavily on Questioning, Advice Giving, Limited Teaching Points, and Patient Updates, under most conditions, with minor variations, primarily for the changing conditions of learner level of training, and patient illness severity, but not increased ED volume. It is likely that all clinical teachers, facing high clinical productivity expectations and/or practicing in demanding urgent care settings, can benefit from adding these teaching methods to their repertoire, adapting the selection of methods to match the resident's level of experience and the severity of the patient's illness. Faculty development and residents' evaluation of teachers can incorporate these findings to enhance resident learning and efficiency. These findings, and others, contribute to the literature on clinical teaching in the $\mathrm{ED}$, by using rigorous methods of observation, to confirm findings previously elicited using interviews and surveys, and to identify additional teaching methods which need further research to confirm.

\section{Conflict of Interest}

The authors declare that they have no conflict of interest.

\section{References}

1. Skeff K, Bowen J, Irby D. Protecting time for teaching in the ambulatory care setting. Acad Med. 1997;72:694-7.

2. Ludmerer K. Time and medical education. Ann Intern Med. 2000;132: 25-8.

3. Bandiera G, Lee S, Tiberius R. Creating effective learning in today's emergency departments: how accomplished teachers get it done. Ann Emerg Med. 2005;45:253-63.

4. Bernstein S, Aronsky D, Duseja R, Epstein S, Handel D, Hwang U, et al. The effect of emergency department crowding on clinically oriented outcomes. Ann Emerg Med. 2009;16:1-10.

5. Atzema C, Bandiera G, Schull M. Emergency department crowding: the effect on resident education. Ann Emerg Med. 2005;45:276-81.

6. Aldeen A, Gisondi M. Bedside teaching in the emergency department. Ann Emerg Med. 2006;13:860-6.

7. Pines J, Prabhu A, McCusker C, Hollander J. The effect of ED crowding on education. Am J Emerg Med. 2010;28:217-20.

8. Kelly S, Shapiro N, Woodruff M, Corrigan K, Sanchez L, Wolfe R. The effects of clinical workload on teaching in the emergency department. Academic Emergency Medicine. 2007;14:526-31.

9. Heidenreich C, Lye P, Simpson D, Lourich M. The search for effective and efficient ambulatory teaching methods through the literature. Pediatrics. 2000;105:231-7.

10. Thurgur L, Bandiera G, Lee S, Tiberius R. What do emergency medicine learners want from their teachers? A multicenter focus group analysis. Academic Emergency Medicine. 2005;12:856-61.

11. Strauss A and Corbin J. Basics of qualitative research: techniques and procedures for developing grounded theory. London. Sage; 1998.

12. Ramani, S. Twelve tips to improve bedside teaching. Medical Teacher. 2003;25:112-15.

13. Irby D, Wilkerson L. Teaching when time is limited. British Medical Journal. 2008;36:384-7.

14. Knowles, MS. The modern practice of adult education: from pedagogy to andragogy.2nd ed. NY: Cambridge Books; 1980.

15. Ende J, Pomerantz A, Erickson F. Preceptors'strategies for correcting residents in an ambulatory care medicine setting: a qualitative analysis. Acad Med. 1995;70:224-29.

16. Irby DM. What clinical teachers in medicine need to know. Acad Med.1994;69:333-42.

17. Dewey J, Experience and education, NY: Touchstone Publisher;1997.

18. Davenport C, Honigman B, Druck J. The three minute emergency medicine medical student presentation: a variation on a theme. Acad Emerg Med. 2008;15:683-7.

19. Irby D, Aagaard E. Teherani A. Teaching points identified by preceptors observing one-minute preceptor and traditional preceptor encounters. Acad Med. 2004;79:50-5.

20. Aagaard E, Teherani A, Irby D. Effectiveness of the one-minute preceptor model for diagnosing the patient and the learner: proof of concept. Acad Med.2004;79:42-9.

21. Neher JO, Stevens N. The one-minute preceptor: shaping the teaching conversation. FamMed. 2003;35:391-3.

22. Wolpaw TM, Wolpaw DR, Papp KK. SNAPPS: a learner-centered model for outpatient education. Acad Med.2003;78:893-8.

23. Wolpaw T, Papp KK, Bordage G. Using SNAPPS to facilitate the expression of clinical reasoning and uncertainties: a randomized comparison group trial. Acad Med.2009;84:517-24.

24. Griffith $\mathrm{CH}$, Georgesen JC, Wilson JF. Six-year documentation of the association between excellent clinical teaching and improved students' examination performances. Acad Med. 2000;75:S62-4.

25. Sofaer S. Qualitative methods: what are they, and why use them? Health Serv Res.1999;34:1101-18.

26. Repp A, Nieminen G, Olinger E, and Brusca R. Direct observation: factors affecting the accuracy of observers. Exceptional Children. 1998;55:29-36.

27. Turnock C and Gibson V. Validity in action research: a discussion on theoretical and practice issues encountered whilst using observation to collect data. J Adv Nurs. 2001;36:471-7. 